\title{
Middle and Distal Common Carotid Artery Stenting: Long-Term Patency Rates and Risk Factors for In-Stent Restenosis
}

\author{
Miklós Vértes $^{1}$ • Dat T. Nguyen ${ }^{1}$ György Székely ${ }^{1}$ Ákos Bérczi ${ }^{1}$ • \\ Edit Dósa ${ }^{1}$
}

Received: 27 January 2020/Accepted: 9 May 2020/Published online: 21 May 2020

(C) The Author(s) 2020

\begin{abstract}
Purpose In the absence of literature data, we aimed to determine the long-term patency rates of middle/distal common carotid artery (CCA) stenting and to investigate predisposing factors in the development of in-stent restenosis (ISR).

Materials and Methods Fifty-one patients (30 males, median age 63.5 years), who underwent stenting with 51 self-expandable stents for significant $(\geq 60 \%)$ stenosis of the middle/distal CCA, were analyzed retrospectively. Patient (atherosclerotic risk factors, comorbidities, medications), vessel (elongation), lesion (stenosis grade, length, calcification, location), and stent characteristics (material, diameter, length, fracture) were examined. Duplex ultrasonography was used to monitor stent patency. The MannWhitney $U$ and Fisher's exact tests, Kaplan-Meier analyses, and a log-rank test were used statistically.

Results The median follow-up time was 35 months (interquartile range, $20-102$ months). Significant ( $\geq 70 \%$ ) ISR developed in 14 patients (27.5\%; stenosis, $N=10$; entire CCA occlusion, $N=4$ ). Primary patency rates were $98 \%, 92 \%, 83 \%, 73 \%$, and $61 \%$ at $6,12,24,60$, and 96 months, respectively. Reintervention was performed in six patients $(11.8 \%)$ with nonocclusive ISR. Secondary patency rates were $100 \%$ at 6 and 12 months and $96 \%$ at 24, 60, and 96 months. In-stent restenosis developed more frequently $(P<.001)$ in patients with hyperlipidemia; primary patency rates were also significantly worse (Chi-
\end{abstract}

Edit Dósa

drdosaedit@gmail.com

1 Heart and Vascular Center, Semmelweis University, Városmajor Street 68, Budapest 1122, Hungary square, 11.08; degrees of freedom, $1 ; P<.001)$ in patients with hyperlipidemia compared to those without.

Conclusion Stenting of the middle/distal CCA can be performed with acceptable patency rates. If intervention is unequivocally needed, patients with hyperlipidemia will require closer follow-up care.

Level of Evidence Level 3, Local non-random sample.

Keywords Carotid artery $\cdot$ Stenting $\cdot$ In-stent restenosis $\cdot$ Hyperlipidemia $\cdot$ Stent fracture

\section{Introduction}

Compared to other locations [carotid bulb, carotid bifurcation, proximal common carotid artery (CCA)], atherosclerotic stenosis rarely occurs in the middle/distal CCA [1]. Neurological symptoms of CCA stenosis caused by hemodynamic insufficiency or distal embolization [2] can be as severe as those of internal carotid artery (ICA) stenosis and may lead to disability and socioeconomic burden [3]. The economic burden is due to direct health care costs, informal care costs, and indirect costs (e.g. social benefit payments and lost income) [4].

Therapeutic options for significant carotid stenosis include best medical treatment (BMT), endovascular intervention, and surgical reconstruction [5-7]. In contrast to proximal CCA stenosis, none of the guidelines provide any recommendation on the type of invasive therapy for middle/distal CCA stenosis [5-7]. In our institution, the indication of invasive therapy for middle/distal CCA 
stenosis is the same as that for the proximal CCA, and percutaneous antegrade stenting is the preferred method.

We were unable to identify publications on the longterm patency of middle/distal CCA stenting and the risk factors for in-stent restenosis (ISR). Most studies focused on proximal CCA stenting and found low ISR rates (0-19\%), with no predictors of ISR [8-14].

In light of the literature, we aimed to investigate the long-term patency rates of middle/distal CCA stenting and the risk factors for ISR.

\section{Materials and Methods}

\section{Patients}

Our study was based on 51 patients in our department who underwent stenting for significant stenosis of the middle and/or distal third of the CCA between 2000 and 2018. The middle/distal CCA was defined as the segment from $30 \mathrm{~mm}$ cranial on the left side and $15 \mathrm{~mm}$ cranial on the right side to the $\mathrm{CCA}$ origin to $10 \mathrm{~mm}$ caudal to the carotid bifurcation.

Institutional Review Board approval was granted, and informed consent was obtained from all patients who had fluoroscopy for evaluation of stent fracture (SF).

\section{Preprocedural Workup and Stenting Protocol}

Diagnosis of middle/distal CCA stenosis was established with duplex ultrasonography (DUS), computed tomography angiography (CTA), or magnetic resonance angiography, and was verified with digital subtraction angiography (DSA) during the procedure. The preprocedural workup and stenting protocol have been described previously [14]. The indication for intervention was the presence of either asymptomatic but $\geq 70 \%$ luminal narrowing $(N=23$ [45.1\%]) or symptomatic and $\geq 60 \%$ stenosis $(N=28$ [54.9\%]). Asymptomatic patients underwent stenting if showing multivessel supra-aortic steno-occlusive disease (Table 1). Also, all asymptomatic patients were thought to have an increased risk for stroke even while on BMT. Patients who had episodes of neurological dysfunction caused by focal carotid territory brain or retinal ischemia within the preceding 6 months were defined as symptomatic [15]. In patients with suspected transient ischemic attack (TIA) or acute stroke, urgent brain CT was performed. Patients were scheduled for stenting within 14 days of the onset of an ischemic neurological event. Treatment decisions were made by our vascular team, which included interventional radiologists, vascular surgeons, and consulting neurologists.
Self-expandable stents were implanted in all patients; predilation was carried out in only two cases, but postdilation was routinely performed (Table 2, Fig. 1). The use of a cerebral protection device (FilterWire EZ, Boston Scientific Corp., Marlborough, MA, USA) was left to the discretion of the interventional radiologist and was applied in 40 cases $(78.4 \%)$. Technical success was defined as $\leq 30 \%$ residual stenosis. Dual antiplatelet therapy was started at least 3 days prior to intervention (or as a single loading dose in urgent cases) and lasted for 1-3 months; after that, if there were no other indications, only single antiplatelet regimen was recommended.

\section{Follow-up}

Follow-up examinations, which were scheduled at 6 weeks, 6 months, 12 months, and then yearly after the stenting, included review of the medical records of the patient, a basic neurological evaluation, and assessment by DUS of the neck arteries on both sides. In patients with abnormal DUS (direct sign: $\geq 300 \mathrm{~cm} / \mathrm{s}$ peak systolic velocity within or at the ends of the CCA stent [7]; indirect sign: tardus-parvus waveform in the ICA [9]), significant $(\geq 70 \%)$ ISR was suspected. Stent occlusion was diagnosed when neither color nor Doppler signal was detected in the stent. The presence of significant ISR/stent occlusion was confirmed by CTA or DSA.

Primary patency was defined as stents without significant ISR. Secondary patency was defined as open stents after endovascular reintervention due to ISR.

\section{Analyzed Parameters}

Patients were divided into two groups based on the presence or absence of significant ISR.

1. Patient data: atherosclerotic risk factors (age, gender, smoking, hypertension, hyperlipidemia, diabetes mellitus, and obesity) and medication regimen (antiplatelet, lipid-lowering, and cilostazol therapies). Hypertension, hyperlipidemia, and diabetes mellitus were assumed to be present if they were noted in the medical reports of the patient, and/or if the patient was taking drugs for the disease or was on insulin therapy for diabetes mellitus. A body mass index of $\geq 30 \mathrm{~kg} /$ $\mathrm{m}^{2}$ was defined as obesity [16].

2. Vessel-related parameter: elongation of the CCA. Elongation was defined as an S- or C-shaped tortuosity or undulation [17].

3. Lesion-related parameters: degree and length of the stenosis, presence and grade of calcification, and location of the lesion (left or right side, middle and/ or distal third). The grade and length of stenosis were 
Table 1 Indications for the treatment of asymptomatic middle/distal common carotid artery stenosis

\begin{tabular}{ll}
\hline Indications, $N(\%)$ & $\begin{array}{c}\text { Patients } \\
(N=23)\end{array}$ \\
\hline Left middle/distal CCA + contralateral ICA significant stenosis & $2(8.7)$ \\
Left middle/distal CCA significant stenosis + contralateral ICA occlusion & $7(30.4)$ \\
Left middle/distal CCA + ipsilateral VA significant stenosis & $1(4.3)$ \\
Left middle/distal CCA + ipsilateral proximal SA significant stenosis & $1(4.3)$ \\
Left middle/distal CCA significant stenosis + ipsilateral proximal SA occlusion & $3(13)$ \\
Left middle/distal CCA significant stenosis + contralateral TIA/stroke & $5(21.7)$ \\
Right middle/distal CCA + contralateral ICA significant stenosis & $2(8.7)$ \\
Right middle/distal CCA significant stenosis + contralateral ICA occlusion & $1(4.3)$ \\
Right middle/distal CCA + ipsilateral proximal SA significant stenosis & $1(4.3)$ \\
\hline
\end{tabular}

$C C A$ Common carotid artery, ICA internal carotid artery, SA subclavian artery, TIA transient ischemic attack, $V A$ vertebral artery

Table 2 Parameters of the stents and balloons

\begin{tabular}{lll}
\hline Stents/balloons & Manufacturer & Size $(\mathrm{mm})$, diameter $\times$ length \\
\hline Self-expandable stents $(N=51)$ & & $7-10 \times 20-50$ \\
Wallstent $(N=39)$ & Boston Scientific Corp., Marlborough, MA, USA & $8-10 \times 40$ \\
Precise Pro $(N=5)$ & Cordis Corp., Johnson \& Johnson Co., Miami, FL, USA & $8-10 \times 40-80$ \\
S.M.A.R.T. Control $(N=4)$ & Cordis Corp., Johnson \& Johnson Co., Miami, FL, USA & $10 \times 100$ \\
Epic $(N=1)$ & Boston Scientific Corp., Marlborough, MA, USA & $9 \times 30$ \\
Exact $(N=1)$ & Abbott Vascular Inc., Santa Clara, CA, USA & $9 \times 30$ \\
Nexstent $(N=1)$ & Boston Scientific Corp., Marlborough, MA, USA & $4 \times 30$ \\
Balloons used for predilation $(N=2)$ & & $4 \times 20$ \\
Emerge $(N=1)$ & Boston Scientific Corp., Marlborough, MA, USA & $7 \times 20$ \\
Sprinter legend RX $(N=1)$ & Medtronic Inc., Minneapolis, MN, USA & $6-8 \times 20-40$ \\
Balloons used for postdilation $(N=51)$ & & $6-7 \times 20-40$ \\
Ultra-soft SV $(N=19)$ & Boston Scientific Corp., Marlborough, MA, USA & $6 \times 20$ \\
Sterling $(N=17)$ & Boston Scientific Corp., Marlborough, MA, USA & 20 \\
Rx Viatrac 14 Plus $(N=10)$ & Abbott Vascular Inc., Santa Clara, CA, USA & \\
Maverick $(N=5)$ & Boston Scientific Corp., Marlborough, MA, USA & \\
\hline
\end{tabular}

assessed on DSA images, as described by Bonati et al. [18], while the presence and grade of calcification were judged on fluoroscopic images, as reported by Doris et al. [19].

4. Stent characteristics: material, diameter, length, and fracture. During follow-up in 2018, patients were asked to return for a fluoroscopic examination of the implanted stents to determine the presence of SF; fractures were categorized according to a classification proposed by Nakazawa et al. [20]. For details of evaluation of SF, please see a publication by Hüttl et al. [21].

\section{Statistical Analysis}

Statistics were calculated using StatSoft Statistica 13.4 (Moonsoft Oy, Espoo, Finland) and GraphPad Prism 7.01 (GraphPad Software Inc., La Jolla, CA, USA) software. Continuous data were presented as medians and interquartile ranges (IQR: Q1, Q3); categorical data were given as counts (percentages). The relationship between ISR and other variables was evaluated with the MannWhitney $U$ test for continuous data and Fisher's exact test for categorical data. A Kaplan-Meier analysis was performed to determine primary and secondary patency rates. Patients were dichotomized based on the presence/absence of the only variable where $P<.05$, and Kaplan-Meier curves of the resulting subsamples were compared with a 
Fig. 1 An example of distal common carotid artery stenting A. Digital subtraction angiography image showing high-grade stenosis in the distal part of the right common carotid artery. B. After implantation of a Wallstent $(7 \times 30 \mathrm{~mm})$, postdilation was performed with a Sterling balloon $(6 \times 20 \mathrm{~mm})$. C. Minimal residual stenosis can be seen on the completion angiogram.

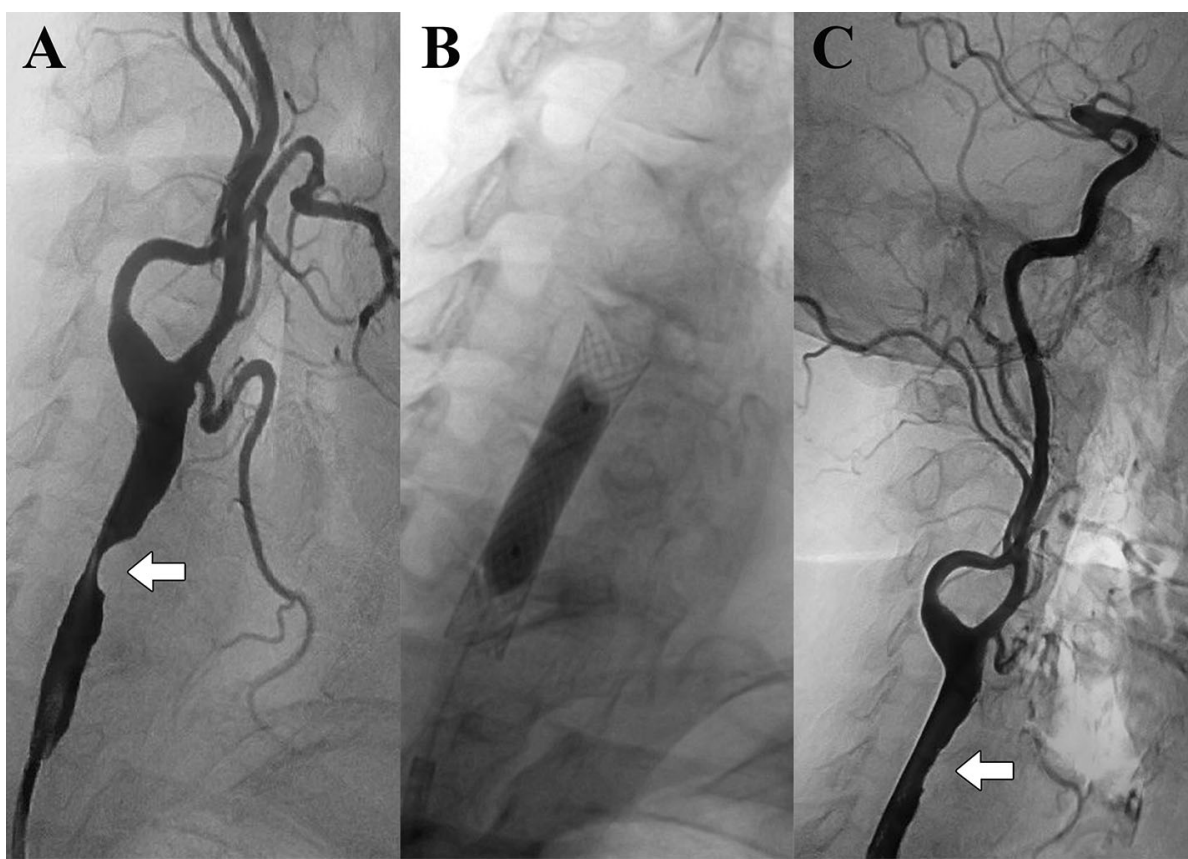

log-rank test. All statistical tests were two-tailed. The threshold of statistical significance was $P<.05$.

\section{Results}

\section{Patient, Vessel, Lesion, and Stent Data}

A total of 68 patients were treated for steno-occlusive disease of the middle/distal CCA during the examined period. Those patients, who had anamnestic history of prior ipsilateral carotid surgery $(N=7)$ or irradiation in the neck region $(N=7)$, or in whom the angiographic or DUS morphology was highly suspicious of carotid fibromuscular dysplasia $(N=2)$ or arteritis $(N=1)$, were excluded from the study. In the remaining 51 patients, who underwent radiological intervention with 51 self-expandable stents (Table 2), atherosclerosis was the putative etiology of the stenosis. Patient-, vessel-, lesion-, and stent-related parameters are summarized in Table 3.

\section{Early Postprocedural Period $(\leq \mathbf{3 0}$ days $)$}

Technical success was achieved in all patients. The following four complications $(7.8 \%)$ were observed: one femoral pseudoaneurysm, which was eliminated by ultrasound-guided injection of thrombin; and one allergic reaction to contrast material causing perioral edema and urticaria, which was treated with chloropyramine and methylprednisolone. Two neurological complications developed: one contralateral hemiparesis plus aphasia that lasted for 5 min after balloon inflation; and one transient contralateral upper extremity numbness. A cerebral protection device was utilized in both these patients, with debris found in the filter of the latter. All neurological symptoms disappeared spontaneously. Computed tomography examination performed within $2 \mathrm{~h}$ of the onset of symptoms revealed no evidence of acute brain ischemia or intracranial arterial obstruction in either patient. The 30-day all-cause mortality rate was zero.

\section{Follow-up Period}

The median follow-up time was 35 months (IQR, 20-102 months). Significant ( $\geq 70 \%$ ) ISR developed in 14 patients $(27.5 \%$; stenosis, $N=10$; entire CCA occlusion, $N=4$ ). Reintervention (percutaneous transluminal angioplasty [PTA] with a plain balloon, $N=5$; restenting, $N=1)$ was conducted in six patients $(11.8 \%)$ with nonocclusive ISR; among them, two patients had ipsilateral TIA, while four had rapid ISR progression on BMT. The remaining patients with nonocclusive ISR or entire CCA occlusion were asymptomatic and received BMT. Recurrent ISR was noted in two cases: one was treated with PTA with a drug-eluting balloon (Ranger, $7 \times 40 \mathrm{~mm}$, Boston Scientific Corp., Marlborough, MA, USA), while the other continued on BMT. Primary and secondary patency rates are shown in Fig. 2. Ischemic neurological symptoms unrelated to the treated CCA were observed in five patients (9.8\%; contralateral TIA, $N=2$; contralateral minor stroke, $N=1$; vertebrobasilar events, $N=2$ ). 
Table 3 Patient-, vessel-, lesion-, and stent-related parameters

\begin{tabular}{|c|c|c|c|c|}
\hline Characteristics & All patients $(N=51)$ & $\begin{array}{l}\text { ISR group } \\
(N=14)\end{array}$ & $\begin{array}{l}\text { Non-ISR group } \\
(N=37)\end{array}$ & $P$ value \\
\hline \multicolumn{5}{|l|}{ Patient-related parameters } \\
\hline \multicolumn{5}{|l|}{ Atherosclerotic risk factors } \\
\hline Age (year), median (IQR) & $63.5(55.2-68.3)$ & $64.2(58.3-66.7)$ & $62.7(55.2-68.7)$ & .908 \\
\hline Female sex, $N(\%)$ & $21(41.2)$ & $8(57.1)$ & $13(35.1)$ & .206 \\
\hline Smoking (current or former), $N(\%)$ & $46(90.2 \%)$ & $12(85.7)$ & $34(91.9)$ & .606 \\
\hline Hypertension, $N(\%)$ & $50(98 \%)$ & $14(100)$ & $36(97.3)$ & $>.999$ \\
\hline Hyperlipidemia, $N(\%)$ & $33(64.7 \%)$ & $14(100)$ & $19(51.4)$ & $<.001$ \\
\hline Diabetes mellitus, $N(\%)$ & $17(33.3 \%)$ & $6(42.9)$ & $11(29.7)$ & .507 \\
\hline BMI $\left(\mathrm{kg} / \mathrm{m}^{2}\right)$, median (IQR) & $26.3(23.2-29.4)$ & $23.5(22-27.9)$ & $26.7(24.2-29.4)$ & .351 \\
\hline Obesity (BMI $\left.\geq 30 \mathrm{~kg} / \mathrm{m}^{2}\right), N(\%)$ & $11(21.6 \%)$ & $3(21.4)$ & $8(21.6)$ & $>.999$ \\
\hline \multicolumn{5}{|l|}{ Medication regimen } \\
\hline Moderate- or high-intensity statin therapy, $N(\%)$ & $38(74.5)$ & $13(92.9)$ & $25(67.6)$ & .081 \\
\hline Other lipid-lowering medication, $N(\%)$ & $1(2)$ & $1(7.1)$ & $0(0)$ & .274 \\
\hline Acetylsalicylic acid therapy, $N(\%)$ & $15(29.4)$ & $4(28.6)$ & $11(29.7)$ & $>.999$ \\
\hline Clopidogrel therapy, $N(\%)$ & $12(23.5)$ & $2(14.3)$ & $10(27)$ & .471 \\
\hline Dual antiplatelet therapy for $1-3$ months, $N(\%)$ & $51(100)$ & $14(100)$ & $37(100)$ & $>.999$ \\
\hline Long-term dual antiplatelet therapy, $N(\%)$ & $24(47.1)$ & $8(57.1)$ & $16(43.2)$ & .531 \\
\hline Cilostazol therapy, $N(\%)$ & $6(11.8)$ & $2(14.3)$ & $4(10.8)$ & .661 \\
\hline \multicolumn{5}{|l|}{ Vessel-related parameter } \\
\hline Elongated CCA, $N(\%)$ & $4(7.8)$ & $2(14.3)$ & $2(5.4)$ & .300 \\
\hline \multicolumn{5}{|l|}{ Lesion-related parameters } \\
\hline Stenosis grade $(\%)$, median (IQR) & $80(75-90)$ & $80(75-90)$ & $80(75-90)$ & .319 \\
\hline Length (mm), median (IQR) & $13(10-20)$ & $14(10-18)$ & $12(9-20)$ & .668 \\
\hline Calcification, $N(\%)$ & $11(21.6 \%)$ & $3(21.4)$ & $8(21.6)$ & $>.999$ \\
\hline Heavy calcification, $N(\%)$ & $6(11.8)$ & $1(7.1)$ & $5(13.5)$ & $>.999$ \\
\hline \multicolumn{5}{|l|}{ Location } \\
\hline Left side, $N(\%)$ & $37(72.5 \%)$ & $12(85.7)$ & $25(67.6)$ & .296 \\
\hline Isolated middle segment, $N(\%)$ & $26(51)$ & $10(71.4)$ & $16(43.2)$ & .116 \\
\hline Isolated distal segment, $N(\%)$ & $22(43.1)$ & $4(28.6)$ & $18(48.6)$ & .224 \\
\hline Middle and distal segments, $N(\%)$ & $3(5.9)$ & $0(0)$ & $3(8.1)$ & .552 \\
\hline \multicolumn{5}{|l|}{ Stent-related parameters } \\
\hline \multicolumn{5}{|l|}{ Material } \\
\hline Elgiloy self-expandable, $N(\%)$ & $39(76.5)$ & $13(92.9)$ & $26(70.3)$ & .141 \\
\hline Diameter (mm), median (IQR) & $8(7-9)$ & $7(7-9)$ & $8(7-9)$ & .227 \\
\hline Length (mm), median (IQR) & $30(30-40)$ & $30(30-40)$ & $40(30-40)$ & .280 \\
\hline Fracture, ${ }^{\mathrm{a}} N(\%)$ & $2(4.3)$ & $0(0)$ & $2(5.9)$ & $>.999$ \\
\hline
\end{tabular}

$B M I$ Body mass index, CCA common carotid artery, IQR interquartile range, ISR in-stent restenosis

${ }^{\text {a }}$ Stent fracture was examined in 47 patients (ISR group, $N=13$; non-ISR group, $N=34$ )

Of 51 patients, $47(92.2 \%)$ returned for a fluoroscopic examination of the implanted stents. Two SFs (4.3\%; one class I: fracture of one strut and one class III: fracture of multiple struts with stent deformity) were detected.

\section{Predictors of In-Stent Restenosis}

In-stent restenosis developed more frequently in patients with hyperlipidemia $(P<.001)$ (Table 3$)$. All patients with ISR had hyperlipidemia. Other patient-, vessel-, lesion-, and stent-related parameters, including SF, did not differ significantly between the two groups (Table 3 ). 
Fig. 2 Primary and secondary patency rates No. Number, $S E$ standard error

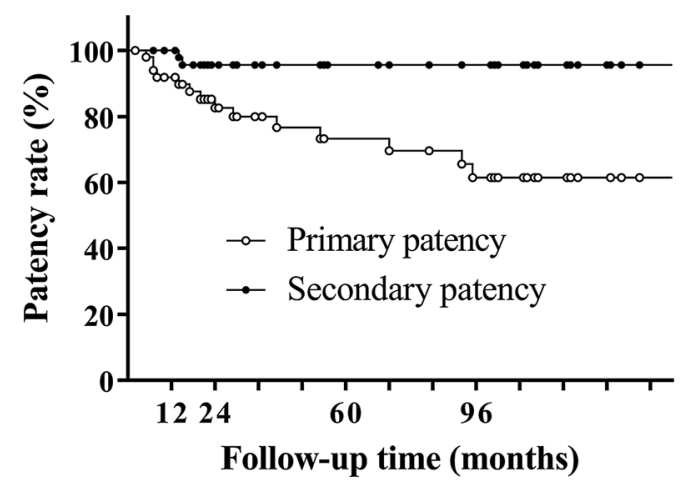

\begin{tabular}{|c|c|c|c|c|c|c|}
\hline Patency & & 6 months & 12 months & 24 months & 60 months & 96 months \\
\hline \multirow{4}{*}{ Primary } & $\%$ & 98 & 91.8 & 82.6 & 73.3 & 61.4 \\
\cline { 2 - 7 } & No. at risk & 49 & 45 & 33 & 21 & 16 \\
\cline { 2 - 7 } & SE & 2 & 3.9 & 5.6 & 7.1 & 8.7 \\
\hline \multirow{3}{*}{ Secondary } & $\%$ & 100 & 100 & 95.6 & 95.6 & 95.6 \\
\cline { 2 - 7 } & No. at risk & 51 & 48 & 36 & 23 & 18 \\
\cline { 2 - 7 } & SE & 0 & 0 & 3 & 3 & 3 \\
\hline
\end{tabular}

The primary patency rate was $100 \%$ at $6,12,24$, and 60 months in patients without hyperlipidemia, while it was $97 \%, 88 \%, 73 \%$, and $58 \%$ at $6,12,24$, and 60 months, respectively, in patients with hyperlipidemia. The primary patency rates were significantly worse (Chi-square, 11.08; degrees of freedom, $1 ; P<.001)$ in patients with hyperlipidemia compared to those without (Fig. 3).

\section{Discussion}

Similarly to ICA stenosis, invasive therapy for CCA stenosis only in symptomatic and those asymptomatic patients with at least one clinical and/or imaging characteristic (history of contralateral TIA/minor stroke; presence of silent brain infarction; detection of stenosis progression and/or large/vulnerable carotid plaque; evidence of spontaneous embolization on transcranial Doppler monitoring;
Fig. 3 Primary patency rates for patients with and without hyperlipidemia No. Number, $S E$ standard error

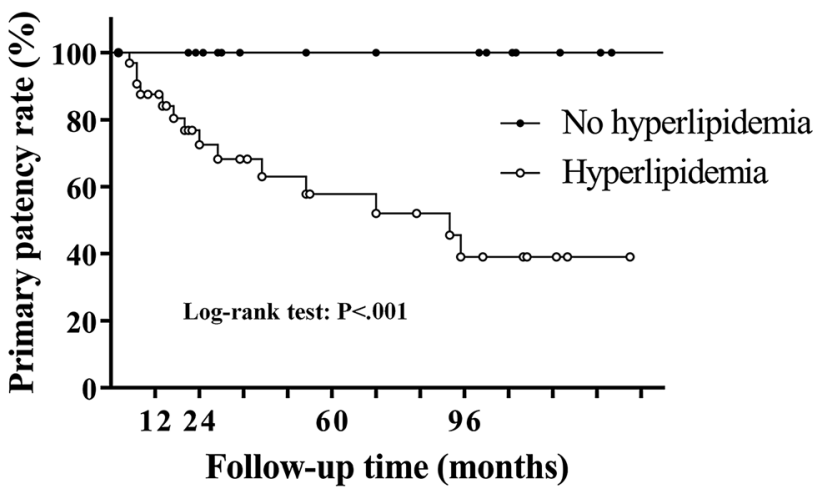

\begin{tabular}{|c|c|c|c|c|c|}
\hline $\begin{array}{c}\text { Primary } \\
\text { patency }\end{array}$ & & $\mathbf{6}$ months & $\mathbf{1 2}$ months & $\mathbf{2 4}$ months & $\mathbf{6 0}$ months \\
\hline \multirow{2}{*}{$\begin{array}{c}\text { No } \\
\text { hyperlipidemia }\end{array}$} & \% & 100 & 100 & 100 & 100 \\
\cline { 2 - 6 } & No. at risk & 18 & 18 & 16 & 11 \\
\cline { 2 - 6 } & SE & 0 & 0 & 0 & 0 \\
\hline \multirow{3}{*}{ Hyperlipidemia } & No. at risk & 32 & 28 & 18 & 11 \\
\cline { 2 - 6 } & SE & 3.1 & 5.8 & 8.4 & 10.2 \\
\cline { 2 - 6 } & & & & & \\
\hline
\end{tabular}


coexistence of intracranial disease, etc.) that makes them at "higher risk for stroke" on BMT is recommended [5, 7, 22]. The Carotid Revascularization and Medical Management for Asymptomatic Carotid Stenosis Trial (CREST-2) is designed to further refine the treatment of asymptomatic patients with high-grade carotid artery stenosis [23], but its final results are still several years away. Nowadays, in case of proximal CCA stenosis, open retrograde stenting is increasingly frequently applied because it minimizes the chance of intraoperative complications and embolic events during and after the procedure $[7,24]$. In contrast to ostial CCA lesions, open retrograde stenting is often technically not feasible in patients with middle/distal CCA stenosis, and the rates of periprocedural stroke and mortality of the open surgical reconstructions are not negligible (1-8\% and $0.4-8 \%$, respectively [25-29]); therefore, in our institute, percutaneous antegrade stenting has become the first treatment of choice for middle/distal CCA steno-occlusive disease.

The technical success rate of percutaneous antegrade stenting of proximal CCA ranges between 95 and $100 \%$ [8-14]. Access site complications were observed in less than $6 \%$ of patients [8-14]. So far, only one procedurerelated death was reported; this was due to retroperitoneal bleeding [8-14]. Transient ischemic attack occurred in 0-5.9\% (ipsilateral, 0-2\%), ipsilateral minor stroke in $0-4.7 \%$, ipsilateral major stroke in 0-2\%, and myocardial infarction in $0-1.5 \%$ within 30 days following antegrade stenting of the proximal CCA [8-14]. In a study by Tang et al., $66.7 \%$ of symptomatic patients were relieved of initial symptoms, and the rest showed improvement [13]. In the current work, the technical success and complication rates were similar to those mentioned above.

The prevalence of proximal CCA ISR is 0-19\% [8-14]. The patency was examined by Paukovits et al., who showed a primary patency rate of $58 \%$ at 60 months in patients who underwent percutaneous antegrade proximal CCA stenting [11]. Our study revealed significant ISR in $27.5 \%$ of patients and a $73 \%$ primary patency rate at 60 months. Our $27.5 \%$ ISR rate is worse than those noted in proximal CCA [8-14]. No definite explanation can be given for our higher ISR rate, but differences in patient, lesion, and stent characteristics among studies can be presumed.

No predictors of CCA ISR have been identified to date. Corresponding to other studies [30, 31], we also evaluated several possible risk factors and found hyperlipidemia to be significantly more common among patients with ISR. The role of hyperlipidemia in the formation of neointimal hyperplasia has also been demonstrated by other research groups [32-36]. Hyperlipidemia increases the entry of lowdensity lipoprotein (LDL) into the intima and its progressive oxidative alteration in the subendothelial space.
Oxidized LDL results in further lipid infiltration across the intact endothelium, where it aggregates and activates the release of mitogens from platelets, macrophages, and endothelial cells; this, in turn, stimulates smooth muscle cell proliferation, thereby leading to neointima formation $[32,33]$.

The middle/distal CCA has not been examined before in the context of SF. The SF rate was reported to be $39 \%$ in patients treated for proximal CCA stenosis [14]. In the present study, the SF rate was much lower (4.3\%). Stent fractures have several known predictors (stent design and length, grade of residual stenosis, etc.) [14, 37-39], but the two most important ones are the location of the stent and calcification of the lesion [14, 37-39]. On the one hand (in general), the low SF rate in this patient population can be explained by the less significant effect of the beating heart and shear forces from the curvature of the aortic arch compared to the proximal CCA. On the other hand (in the current study), the number of heavily calcified lesions was not deemed to be considerable.

Our results should be regarded in the light of several limitations. First, the study was retrospective in nature. Second, the sample size was small and inhomogeneous, which did not permit detailed regression analyses in terms of risk factors for ISR or stent occlusion. Third, not all patients had CTA preprocedurally; therefore, fluoroscopic images were used to judge the presence and grade of calcification. Fourth, different stents were implanted in the middle/distal CCA.

\section{Conclusion}

Stenting of the middle/distal CCA can be performed with acceptable patency rates. If intervention is unequivocally needed, patients with hyperlipidemia would require closer follow-up care. Further studies with a larger and more homogeneous sample may be necessary to confirm our results and to be able to perform important subgroup analyses.

Acknowledgements Open access funding provided by Semmelweis University (SE).

Funding This study was not supported by any funding.

\section{Compliance with Ethical Standards}

Conflict of interest The authors declare that they have no conflict of interest.

Ethical Approval All procedures performed in studies involving human participants were in accordance with the ethical standards of the institutional and/or national research committee and with the 1964 Helsinki declaration and its later amendments or comparable ethical 
standards. The study protocol has obtained Institutional Review Board approval from the Semmelweis University Regional and Institutional Committee of Science and Research Ethics (Approval No. 174/2018).

Informed Consent Informed consent was obtained from all individual participants who had fluoroscopy for evaluation of stent fracture.

Open Access This article is licensed under a Creative Commons Attribution 4.0 International License, which permits use, sharing, adaptation, distribution and reproduction in any medium or format, as long as you give appropriate credit to the original author(s) and the source, provide a link to the Creative Commons licence, and indicate if changes were made. The images or other third party material in this article are included in the article's Creative Commons licence, unless indicated otherwise in a credit line to the material. If material is not included in the article's Creative Commons licence and your intended use is not permitted by statutory regulation or exceeds the permitted use, you will need to obtain permission directly from the copyright holder. To view a copy of this licence, visit http://creativecommons. org/licenses/by/4.0/

\section{References}

1. Bonati LH, Brown MM. Carotid artery disease. In: Grotta JC, Albers GW, Broderick JP, Kasner SE, Lo EH, Mendelow AD, Sacco RL, Wong LKS, editors. Stroke: pathophysiology, diagnosis, and management. Amsterdam: Elsevier-Health Sciences Division; 2016. p. 326.

2. Qaja E, Tadi P, Theetha Kariyanna P. Carotid Artery Stenosis. [Updated $2020 \mathrm{Feb}$ 27]. In: Stat pearls [Internet]. Treasure Island (FL): Stat Pearls Publishing; 2020 Jan-Available from: https:// www.ncbi.nlm.nih.gov/books/NBK442025/. Accessed 8 April 2020.

3. Gorelick PB. The global burden of stroke: persistent and disabling. Lancet Neurol. 2019;18:417-8.

4. Saka OR, McGuire A, Wolfe CDA. Economic burden of Stroke in England. Division of Health and Social Care Research, King's College London. 2005. https://www.nao.org.uk/wp-content/ uploads/2005/11/0506452_economic_analysis.pdf. Accessed 8 April 2020.

5. Aboyans V, Ricco J-B, Bartelink M-LEL, Björck M, Brodmann M, Cohnert T, et al. Editor's choice-2017 ESC guidelines on the diagnosis and treatment of peripheral arterial diseases, in collaboration with the European society for vascular surgery (ESVS). Eur Heart J. 2018;39:763-816.

6. Brott TG, Halperin JL, Abbara S, Bacharach JM, Barr JD, Bush RL, et al. 2011 ASA/ACCF/AHA/AANN/AANS/ACR/ASNR/ CNS/SAIP/SCAI/SIR/SNIS/SVM/SVS guideline on the management of patients with extracranial carotid and vertebral artery disease. J Am Coll Cardiol. 2011;57:1002-444.

7. Naylor AR, Ricco JB, de Borst GJ, Debus S, de Haro J, Halliday A, et al. Editor's choice-management of atherosclerotic carotid and vertebral artery disease: 2017 clinical practice guidelines of the European society for vascular surgery (ESVS). Eur J Vasc Endovasc Surg. 2018;55:3-81.

8. Ben Ahmed S, Benezit M, Hazart J, Brouat A, Daniel G, Rosset E. Outcomes of the endovascular treatment for the supra-aortic trunks occlusive disease: a 14-year monocentric experience. Ann Vasc Surg. 2016;33:55-66.

9. Cam A, Muhammad KI, Shishehbor MH, Bajzer CT, Kapadia SR. Technique and outcome of ostial common carotid artery stenting: a single centre experience. EuroIntervention. 2012;7:1210-5.

10. Chio FL Jr, Liu MW, Khan MA, Iyer SS, Roubin GS. Effectiveness of elective stenting of common carotid artery lesions in preventing stroke. Am J Cardiol. 2003;92:1135-7.

11. Paukovits TM, Haász J, Molnár A, Szeberin Z, Nemes B, Varga $D$, et al. Transfemoral endovascular treatment of proximal common carotid artery lesions: a single-center experience on 153 lesions. J Vasc Surg. 2008;48:80-7.

12. Peterson BG, Resnick SA, Morasch MD, Hassoun HT, Eskandari MK. Aortic arch vessel stenting: a single-center experience using cerebral protection. Arch Surg. 2006;141:560-3.

13. Tang X, Long WA, Hu C, Tang F, Wang Q, Li L. The modified 'no touch' technique in the antegrade endovascular approach for left common carotid artery ostial stenosis stenting. J Neurointerv Surg. 2017;9:137-41.

14. Vértes M, Nguyen DT, Székely G, Bérczi Á, Dósa E. The incidence and risk factors of stent fracture in patients treated for proximal common carotid artery stenosis. J Vasc Surg. 2020;71:824-31.

15. Sacco RL, Kasner SE, Broderick JP, Caplan LR, Connors JJ, Culebras A, et al. An updated definition of stroke for the twenty first century: a statement for healthcare professionals from the American heart association/American stroke association. Stroke. 2013;44:2064-89.

16. Rezaianzadeh A, Namayandeh SM, Sadr SM. National cholesterol education program adult treatment panel III versus international diabetic federation definition of metabolic syndrome, which one is associated with diabetes mellitus and coronary artery disease? Int J Prev Med. 2012;3:552-8.

17. Ciurica S, Lopez-Sublet M, Loeys BL, Radhouani I, Natarajan N, Vikkula M, et al. Arterial tortuosity. Hypertension. 2019;73:951-60.

18. Bonati LH, Ederle J, Dobson J, Engelter S, Featherstone RL, Gaines PA, et al. Length of carotid stenosis predicts peri-procedural stroke or death and restenosis in patients randomized to endovascular treatment or endarterectomy. Int $\mathrm{J}$ Stroke. 2014;9:297-305.

19. Doris I, Dobranowski J, Franchetto AA, Jaeschke R. The relevance of detecting carotid artery calcification on plain radiograph. Stroke. 1993;24:1330-4.

20. Nakazawa G, Finn AV, Vorpahl M, Ladich E, Kutys R, Balazs I, et al. Incidence and predictors of drug-eluting stent fracture in human coronary artery a pathologic analysis. J Am Coll Cardiol. 2009;54:1924-31.

21. Hüttl AB, Hüttl A, Vértes M, Nguyen DT, Bérczi Á, Hüttl K, et al. The presence of long and heavily calcified lesions predisposes for fracture in patients undergoing stenting of the first part of the subclavian artery. J Vasc Surg. 2019;70:1146-54.

22. Naylor AR, Schroeder TV, Sillesen H. Clinical and imaging features associated with an increased risk of late stroke in patients with asymptomatic carotid disease. Eur J Vasc Endovasc Surg. 2014;48:633-40.

23. Mott M, Koroshetz W, Wright CB. CREST-2: identifying the best method of stroke prevention for carotid artery stenosis: national institute of neurological disorders and stroke organizational update. Stroke. 2017;48:e130-e131131.

24. Balceniuk MD, Hosn MA, Corn RS, DerDerian T, Grimsley BR, Long $\mathrm{P}$, et al. Endovascular stenting of supra-aortic lesions using a transcarotid retrograde approach and flow reversal: a multicenter case series. J Vasc Surg. 2019 Nov 15. [Epub ahead of print]

25. Aziz F, Gravett MH, Comerota AJ. Endovascular and open surgical treatment of brachiocephalic arteries. Ann Vasc Surg. 2011;25:569-81. 
26. Berguer R, Morasch MD, Kline RA. Transthoracic repair of innominate and common carotid artery disease: immediate and long-term outcome for 100 consecutive surgical reconstructions. J Vasc Surg. 1998;27:34-41 discussion 42.

27. Daniel VT, Madenci AL, Nguyen LL, Eslami MH, Kalish JA, Farber A, et al. Contemporary comparison of supra-aortic trunk surgical reconstructions for occlusive disease. J Vasc Surg. 2014;59:1577-82.

28. Takach TJ, Reul GJ, Cooley DA, Duncan JM, Livesay JJ, Gregoric ID, et al. Brachiocephalic reconstruction I: operative and long-term results for complex disease. J Vasc Surg. 2005;42:47-544.

29. Takach TJ, Duncan JM, Livesay JJ, Krajcer Z, Cervera RD, Gregoric ID, et al. Brachiocephalic reconstruction II: operative and endovascular management of single-vessel disease. J Vasc Surg. 2005;42:55-61.

30. Dai Z, Xu G. Restenosis after carotid artery stenting. Vascular. 2017;25:576-86.

31. Van Laanen J, Hendriks JM, Van Sambeek MR. Factors influencing restenosis after carotid artery stenting. J Cardiovasc Surg (Torino). 2008;49:743-7.

32. Dósa E, Hirschberg K, Apor A, Járányi Z, Entz L, Acsády G, et al. Echolucent or predominantly echolucent femoral plaques predict early restenosis after eversion carotid endarterectomy. J Vasc Surg. 2010;51:345-50.

33. Aidinian G, Weiswasser JM, Arora S, Abularrage CJ, Singh N, Sidawy AN. Carotid plaque morphologic characteristics. Perspect Vasc Surg Endovasc Ther. 2006;18:63-70.
34. Lal BK, Beach KW, Roubin GS, Lutsep HL, Moore WS, Malas $\mathrm{MB}$, et al. Restenosis after carotid artery stenting and endarterectomy: a secondary analysis of CREST, a randomised controlled trial. Lancet Neurol. 2012;11:755-63.

35. Mansour OY, Ibrahim A, Talaat M. Restenosis predictors after carotid angioplasty and stenting and its influence on procedure durability, single-center experience. J Stroke Cerebrovasc Dis. 2017;26:2215-22.

36. Zhang LN, Parkinson JF, Haskell C, Wang YX. Mechanisms of intimal hyperplasia learned from a murine carotid artery ligation model. Curr Vasc Pharmacol. 2008;6:37-433.

37. Chinikar M, Sadeghipour P. Coronary stent fracture: a recently appreciated phenomenon with clinical relevance. Curr Cardiol Rev. 2014;10:349-54.

38. Lin Y, Tang X, Fu W, Kovach R, George JC, Guo D. Stent fractures after superficial femoral artery stenting: risk factors and impact on patency. J Endovasc Ther. 2015;22:319-26.

39. McElhinney DB, Marshall AC, Schievano S. Fracture of cardiovascular stents in patients with congenital heart disease: theoretical and empirical considerations. Circ Cardiovasc Interv. 2013;6:575-85.

Publisher's Note Springer Nature remains neutral with regard to jurisdictional claims in published maps and institutional affiliations. 